\title{
A proposed surface resistance model for the Penman-Monteith formula to estimate evapotranspiration in a solar greenhouse
}

\author{
GONG Xuewen ${ }^{1,2}$, LIU Hao ${ }^{1}$, SUN Jingsheng ${ }^{1 *}$, GAO Yang ${ }^{1}$, ZHANG Xiaoxian ${ }^{3}$, Shiva K \\ $\mathrm{JHA}^{2,4}$, ZHANG Hao ${ }^{1,2}$, MA Xiaojian ${ }^{1,2}$, WANG Wanning ${ }^{1,2}$ \\ ${ }^{1}$ Key Laboratory of Crop Water Use and Regulation, Ministry of Agriculture, Farmland Irrigation Research Institute, Chinese \\ Academy of Agricultural Sciences, Xinxiang 453003, China; \\ ${ }^{2}$ Graduate School of Chinese Academy of Agricultural Sciences, Beijing 100081, China; \\ ${ }^{3}$ Department of Sustainable Soils and Grassland Systems, Rothamsted Research, Harpenden, Hertfordshire AL5 2JQ, United \\ Kingdom; \\ ${ }^{4}$ National Maize Research Program, Nepal Agricultural Research Council, Chitwan 44209, Nepal
}

\begin{abstract}
Greenhousing is a technique to bridge season gap in vegetable production and has been widely used worldwide. Calculation of water requirement of crops grown in greenhouse and determination of their irrigation schedules in arid and semi-arid regions are essential for greenhouse maintenance and have thus attracted increased attention over the past decades. The most common method used in the literature to estimate crop evapotranspiration (ET) is the Penman-Monteith (PM) formula. When applied to greenhouse, however, it often uses canopy resistance instead of surface resistance. It is understood that the surface resistance in greenhouse is the result of a combined effect of canopy restriction and soil-surface restriction to water vapor flow, and the relative dominance of one restriction over another depends on crop canopy. In this paper, we developed a surface resistance model in a way similar to two parallel resistances in an electrical circuit to account for both restrictions. Also, considering that wind speed in greenhouse is normally rather small, we compared three methods available in the literature to calculate the aerodynamic resistance, which are the $r_{a}$ method proposed by Perrier $(1975 \mathrm{a}, \mathrm{b})$, the $r_{a} 2$ method proposed by Thom and Oliver (1977), and the $r_{a^{3}}$ method proposed by Zhang and Lemeu (1992). We validated the model against ET of tomatoes in a greenhouse measured from sap flow system combined with micro-lysimeter in 2015 and with weighing lysimeter in 2016. The results showed that the proposed surface resistance model improved the accuracy of the PM model, especially when the leaf area index was low and the greenhouse was being irrigated. We also found that the aerodynamic resistance calculated from the $r_{a}$ and $r_{a}$ methods is applicable to the greenhouse although the latter is slightly more accurate than the former. The proposed surface resistance model, together with the $r_{a}$ method for aerodynamic resistance, offers an improved approach to estimate ET in greenhouse using the PM formula.
\end{abstract}

Keywords: canopy resistance; surface resistance; aerodynamic resistance; sap flow system; micro-lysimeter; weighing lysimeter

Citation: GONG Xuewen, LIU Hao, SUN Jingsheng, GAO Yang, ZHANG Xiaoxian, Shiva K JHA, ZHANG Hao, MA Xiaojian, WANG Wanning. 2017. A proposed surface resistance model for the Penman-Monteith formula to estimate evapotranspiration in a solar greenhouse. Journal of Arid Land, 9(4): 530-546. doi: 10.1007/s40333-017-0020-8

*Corresponding author: SUN Jingsheng (E-mail: jshsun623@163.com)

The first and second authors contribute equally to this work.

Received 2016-12-23; revised 2017-04-23; accepted 2017-05-05

(C) Xinjiang Institute of Ecology and Geography, Chinese Academy of Sciences, Science Press and Springer-Verlag Berlin Heidelberg 2017 


\section{Introduction}

The simple-structured solar greenhouses have emerged as a favorite technique over the past few years in northern China because they bridge the season gap in vegetable and fruit production (Wei and Sun, 2014). Most solar greenhouses need irrigation and, currently, the irrigation schedule for greenhouse is largely empirical, often resulting in water waste (Guo et al., 2005). Improving water use efficiency is hence essential to decrease the costs and thus to increase the profits of the greenhouse farmers.

Evapotranspiration $(E T)$ is an important parameter for determining irrigation schedule (Yuan et al., 2001; Zheng et al., 2016) in arid and semi-arid regions that rely on irrigation for agricultural production. In practice, the evapotranspiration can be directly measured using sap flow system in combination with micro-lysimeter or weighing/drainage lysimeter. But, this method is more expensive to operate and also subject to temporal and spatial restrictions in certain circumstances. Given the limitation of the above-mentioned direct method, mathematical models, such as the Penman-Monteith (PM) formula, have been widely used to provide an effective alternative to estimate crop ET (Monteith, 1965). The PM formula needs two resistances: one is surface resistance $\left(r_{s}\right)$ and the other is aerodynamic resistance $\left(r_{a}\right)$. The $r_{s}$ describes the resistance of surface to water vapor flow through the stomata openings depending on total leaf area and soil surface, while the $r_{a}$ describes the resistance caused by vegetation to upward flow of water vapor depending on the friction between air flow and the vegetative surface (Monteith, 1965). Although the exchange processes in vegetation layer are too complicated to be described simply by the two resistances, a good correlation has been found between measured and estimated ET when the canopy of crops is dense (Monteith, 1965; Allen et al., 1998). Currently, the PM formula for greenhouses focuses on canopy layer because most greenhouses are either mulched (Bailey et al., 1993; Qiu et al., 2013) or grow crops in a hydroponic culture (Zhang and Lemeur, 1992; Rouphael and Colla, 2004). As such, the canopy resistance is often used as the overall resistance in the PM formula when applied to greenhouse. In northern China, however, most solar greenhouses do not need mulching when growing tomato and the evaporation from soil surfaces hence needs to be considered in analyzing water vapor balance. Under this condition, the PM formula needs to consider the integrative impact of both plant canopy and soil surface on water vapor flow, which can be described by canopy resistance and soil resistance, respectively. In general, using canopy resistance rather than bulk surface resistance underestimates the surface resistance, leading to an overestimated ET (Li et al., 2015). A number of complicated surface resistance models have been developed to address this issue, considering both surface resistance and canopy resistance in a way similar to a parallel circuit. For example, Iritz et al. (1999) showed that combining soil and canopy resistances with the aerodynamic resistance from soil to canopy improved the estimate of the surface resistance. Rajan et al. (2010) calculated the surface resistance using soil and canopy resistances by introducing a ground cover parameter. Li et al. (2015) proposed a coupled surface resistance model by combining the Jarvis canopy resistance model and the soil resistance model; Juhász and Hrotkó (2014) also proposed a similar model. However, these models focused on field and could give rise to considerable errors when applied to greenhouses. It is hence helpful to develop an integrative surface resistance model considering both soil and canopy resistances to estimate $E T$ in solar greenhouse.

The approaches for calculating the $r_{a}$ in the PM formula can be grouped into two methods. The first one is to use a function depending on wind speed, plant height and vegetation distribution; the second one is to express $r_{a}$ as a function of heat transfer coefficient $(h)$ as shown in Zhang and Lemeur (1992). In the first method, there is no consensus about whether the wind speed should be considered. Perrier (1975a, b) stated that the wind speed should be included because the effect of wind speed on latent heat flux was mainly achieved by changing the $r_{a}$. The transfer of water vapor in the surfaces of leaf stomata and soil is driven by wind speed and an increase in wind speed could result in a decrease in resistance to water-vapor diffusion, thereby enhancing crop transpiration and soil evaporation. Previous studies have showed that such approach works well in different types of greenhouses (Möller et al., 2004; Villarreal-Guerrero et al., 2012), but could 
result in errors when wind speed in greenhouse is close to zero as the aerodynamic resistance calculated by this model approaches infinite when wind speed is close to zero. An improvement is to calculate the aerodynamic resistance using the method proposed by Thom and Oliver (1977), which, as shown by Later Chen et al. (2007) and Liu et al. (2011), is an appropriate approach for solar greenhouse when the wind speed is zero or close to zero. However, the wind speed in some greenhouses with ventilation could be more than $0.4 \mathrm{~m} / \mathrm{s}$ (Wang et al., 1999) and the accuracy of this method under ventilation hence needs further improvement. In the second method, Zhang and Lemeur (1992) stated that the heat transfer between canopy and atmosphere is convective and that $r_{a}$ can be calculated using the heat transfer coefficient. Free, forced, and mixed convections exist in different climatic zones (Bailey et al., 1993; Montero et al., 2001; Rouphael and Colla, 2004), but it is difficult to determine which convection is dominant in a greenhouse. Stanghellini (1993) showed that the convective transfer of heat and mass to and from canopy is due to the mixed convection, despite low wind speed within it. Later, Qiu et al. (2013) also showed that the mixed convection is dominant during daytime in the Northwest China. However, calculating the heat transfer coefficient needs canopy temperature which is difficult to be measured, giving rise to uncertainties when using this method to estimate $r_{a}$, especially when the canopy is spatially sparse. Currently, there is a lack of study on how to calculate the aerodynamic resistance in different growing stages in solar greenhouses.

As stated above, the aims of this study are (1) to develop and evaluate the performance of a surface resistance model under different conditions; and (2) to compare three methods for calculating the aerodynamic resistance in a solar greenhouse.

\section{Materials and methods}

\subsection{Study area}

The experiments were conducted from March to July in both 2015 and 2016 in a solar greenhouse at the Experimental Station of Farmland Irrigation Research, Institute of Chinese Academy of Agricultural Sciences $\left(35^{\circ} 09^{\prime} \mathrm{N}, 113^{\circ} 47^{\prime} \mathrm{E}\right.$; $78.7 \mathrm{~m}$ a.s.l.), Xinxiang City, Henan Province, China. The annual precipitation and potential evaporation in the station were 548 and $1908 \mathrm{~mm}$, respectively, with an annual mean air temperature of $14^{\circ} \mathrm{C}$, sunshine duration of $2398 \mathrm{~h}$, and frost-free days of $200 \mathrm{~d}$. The solar greenhouse was made by a steel frame with a covering area of $510 \mathrm{~m}^{2}(60 \mathrm{~m} \times 8.5 \mathrm{~m})$ and covered by a $0.2-\mathrm{mm}$ thick non-drop polyethylene sheet. The roof of the greenhouse was cotton-quilts with $2.5-\mathrm{cm}$ thick cotton wadding, and the heat-insulating materials were mounted in the back wall to maintain interior temperature. The greenhouse was equipped with a ventilation system to adjust its temperature and humidity. The soil used in the experiment was loam, with a mean bulk density of $1.51 \mathrm{~g} / \mathrm{cm}^{3}$, field capacity of $0.366 \mathrm{~cm}^{3} / \mathrm{cm}^{3}$ and wilting-point water content of $0.09 \mathrm{~cm}^{3} / \mathrm{cm}^{3}$ in the depth of $0-90 \mathrm{~cm}$.

\subsection{Experimental design}

Tomato (Lycopersicon esculentum Mill. cv. Jingding) was planted in 18 plots. Each plot was 8.8 $\mathrm{m}^{2}(8.0 \mathrm{~m} \times 1.1 \mathrm{~m})$ with 50 plants planted in two rows. The distance between the two rows alternated from 65 to $45 \mathrm{~cm}$ in the 18 plots. The plants were watered by drip irrigation and the spatial interval of the emitters in each drip tape was $33 \mathrm{~cm}$. The designed discharge rate of each drip tape was $1.1 \mathrm{~L} / \mathrm{h}$. The irrigation frequencies were determined based on the cumulative evaporation $\left(E_{p}\right)$ measured from a pan of $20 \mathrm{~cm}$ in diameter placed $30 \mathrm{~cm}$ above the canopy at the center of the greenhouse. When $E_{p}$ reached to $20( \pm 2) \mathrm{mm}$, irrigation started and the plant-pan coefficient of 0.9 was used in this experiment (Liu et al., 2013). Therefore, the amount of applied irrigation water can be calculated by the equation $I_{r}=0.9 \times E_{p}$, where $E_{p}$ is the cumulative evaporation from $20 \mathrm{~cm}$ diameter pan $(\mathrm{mm})$. To ensure seeding growth, we irrigated $20 \mathrm{~mm}$ of water to all plots just after the transplanting. The plants were irrigated 14 times in each of the two seasons, and the total irrigation amount was $282.4 \mathrm{~mm}$ in 2015 and $280.7 \mathrm{~mm}$ in 2016 . During the experiments, we adopted a method similar to that used by local farmers to maintain the greenhouses, including fertilization application, pollination, and pest control. 


\subsection{Methods}

\subsubsection{Evapotranspiration measurements}

Evapotranspiration $(E T)$ of the tomato was measured using sap flow system combined with micro-lysimeters in 2015 and with weighing lysimeters in 2016.

Soil evaporation was measured daily from a micro-lysimeters from 17 March to 15 July, 2015. The micro-lysimeter was made from galvanized iron, consisting of an inner cylinder and an outer cylinder. The diameters of the inner and outer cylinders were 10 and $12 \mathrm{~cm}$, respectively, and its height was $15 \mathrm{~cm}$. For easy operation without physically disturbing the soil, the outer tank was fixed into the soil with its top level with the soil surface. The inner cylinder was then pushed into the soil until its top was leveled with the soil surface. The base of the micro-lysimeter was sealed by a plastic foil to avoid percolation. The inner cylinder was weighted daily at 08:00 using an electronic balance with a precision of $0.1 \mathrm{~g}$, and the soil evaporation was defined as the difference between two consecutive weights. To ensure the accuracy, we replaced the soil in the inner tank every two days or after irrigation. In each of six randomly selected plots, these micro-lysimeters were installed between two neighboring plants in the same row as well as between two neighboring plants in two different rows, respectively, each having two replicates.

A sap flow system (Flow32-1k system, Dynamax, Houston, TX, USA) was used to measure the transpiration. In each plot, the SGA-WS gauges of the sap flow (DYNAMAX Inc., USA) were installed at representative plants of the tomatoes. Eight health plants were randomly selected and their stem diameters were measured prior to installing the gauges. The measured stem diameters varied from 9.0 to $12.0 \mathrm{~mm}$. Therefore, the SGA9-WS/SGA10-WS and SGB12-WS gauges were used to measure the sap flow. The gauges were fixed on the stems $20 \mathrm{~cm}$ above the ground surface to avoid the effect of surface heat flux (Qiu et al., 2015). The details of the installation and measurements of the sap flow system can be found in Gao et al. (2013). Sap flow from 15 May to 15 July, 2015 was measured, in which the sap flow data were collected after every 15 min by a CR-1000 data logger (Campbell Scientific Inc., USA). The sap flow of each individual plant was then converted to plant transpiration using the following formula (Ham et al., 1990):

$$
T=\frac{1}{1000}\left[\sum_{i=1}^{n} \frac{f_{i} / L A_{i}}{n}\right] L A I,
$$

where, $T$ is the plant transpiration after normalizing the sap flow data by the leaf area $(\mathrm{mm} / \mathrm{h}) ; f_{i}$, the stem flow $(\mathrm{g} / \mathrm{h}) ; L A_{i}$, the leaf area $\left(\mathrm{m}^{2}\right) ; n$, the number of plants measured; and $L A I$, the leaf area index $\left(\mathrm{m}^{2} / \mathrm{m}^{2}\right)$.

ET was measured by two weighing lysimeters (1.0 m long, $1.0 \mathrm{~m}$ wide and $1.2 \mathrm{~m}$ deep) located in the center of the plots from 9 March to $10 \mathrm{July,} 2016$. The weighing lysimeter can measure up to 2.5 tons with a precision of $0.01 \mathrm{~mm}$, and the data were collected after every 60 min by a microcomputer. The planting pattern in the weighing lysimeter was the same as the outside. There were six health plants in each weighing lysimeter. To avoid interferences with plants outside, we popped up all the six plants by bamboo sticks.

2.3.2 Soil water content and leaf area index

Soil water content was measured using the $\mathrm{ECH}_{2} \mathrm{O}$ soil moisture monitoring system. Five $\mathrm{ECH}_{2} \mathrm{O}$ soil moisture probes were placed at depths of 10, 20,30,40, and $60 \mathrm{~cm}$, respectively. The soil water content data were collected after each 30 min using the EM50 data logger (Decagon Devices Inc., USA).

The leaf area was measured manually at an interval of 5-10 days. Thirty plants were sampled at the center of each plot. The leaf length $(L)$ and the greatest leaf width $\left(W_{m}\right)$ were measured with a ruler, and the conversion coefficient of 0.64 for the leaf area was obtained from fitting the measured results to that drawn using CAD software (Liu et al., 2009). LAI was calculated as follows:

$$
L A I=\frac{\sum_{i=1}^{n}\left(L \times W_{m} \times 0.64\right)_{i}}{S_{R} \times S_{p}},
$$


where, $S_{R}(55 \mathrm{~cm})$ is the average row space, and $S_{p}(33 \mathrm{~cm})$ is the average distance between two neighboring plants.

\subsubsection{Leaf stomatal resistance}

The leaf stomatal resistance was directly measured using a porometer (SC-1, Decagon Devices Inc., USA) at an interval of 7-10 days. In each plot, 6-9 functional leaves of healthy plants were randomly selected. Diurnal variations of the leaf stomatal resistance were measured at seedling, flowering-fruit bearing, full fruit, and picking stages.

\subsubsection{Meteorological data}

The solar radiation $\left(R_{s}\right)$, net radiation $\left(R_{n}\right)$, relative humidity $(R H)$, air temperature $\left(T_{a}\right)$ and wind speed $(u)$ were measured using an automatic weather station installed $2.0 \mathrm{~m}$ above the ground surface. The $R_{s}$ was measured by a radiometer (LI200X, Campbell Scientific Inc., USA) with sensitivity of $0.2 \mathrm{~kW} /\left(\mathrm{m}^{2} \cdot \mathrm{mV}\right)$, and the $R_{n}$ was measured by a net radiometer (NR LITE2, Kipp \& Zonen, Delft, Netherlands) with sensitivity of $10 \mu \mathrm{V} /\left(\mathrm{W} \cdot \mathrm{m}^{2}\right)$. The $T_{a}$ and $R H$ were measured by a temperature and relative humidity recorder (CS215, Campbell Scientific Inc., USA). The $u$ was recorded by an air velocity meter (Wind Sonic, Gill, UK) with an accuracy of $\pm 0.02 \mathrm{~m} / \mathrm{s}$. The surface temperature $\left(T_{S}\right)$ was measured using an infrared radiation pyrometer (SI-111, Campbell Scientific Inc., USA) with an accuracy of $\pm 0.2^{\circ} \mathrm{C}$, which is mounted $30 \mathrm{~cm}$ above the canopy with its sensor approximately $45^{\circ}$ to the horizon of the canopy pointing northward. The soil heat flux $(G)$ was measured at two points, one between two plants in a row and the other between two rows, using the heat flux plates (HFP01, Hukseflux, Netherlands) with sensitivity of $50 \mu \mathrm{V} /\left(\mathrm{W} \cdot \mathrm{m}^{2}\right)$, installed $5 \mathrm{~cm}$ below the ground surface. All measurements were collected after each $10 \mathrm{~s}$, and the averages over $30 \mathrm{~min}$ were calculated and the results were stored in a CR-1000 data logger (Campbell Scientific Inc., USA). The maximum, minimum, and mean of daily averages of all meteorological parameters measured in 2015 and 2016 are shown in Table 1.

Table 1 The maximum, minimum and mean of daily averages of meteorological data measured in 2015 and 2016

\begin{tabular}{ccccccccc}
\hline Year & Statistic & $R_{s}\left(\mathrm{~W} / \mathrm{m}^{2}\right)$ & $R_{n}\left(\mathrm{~W} / \mathrm{m}^{2}\right)$ & $T_{a}\left({ }^{\circ} \mathrm{C}\right)$ & $T_{s}\left({ }^{\circ} \mathrm{C}\right)$ & $V P D(\mathrm{kPa})$ & $R H(\%)$ & $u(\mathrm{~m} / \mathrm{s})$ \\
\hline \multirow{2}{*}{2015} & Maximum & 231.14 & 172.57 & 31.33 & 29.09 & 2.46 & 99.78 & 0.43 \\
& Minimum & 25.17 & 16.19 & 15.41 & 15.87 & 0.02 & 47.86 & 0.06 \\
& Mean & 136.96 & 94.64 & 24.30 & 23.10 & 0.77 & 82.06 & 0.14 \\
\multirow{2}{*}{2016} & Maximum & 207.09 & 175.32 & 31.75 & 29.06 & 1.95 & 99.39 & 0.34 \\
& Minimum & 8.60 & 3.08 & 11.40 & 14.62 & 0.02 & 52.24 & 0.05 \\
& Mean & 128.12 & 98.40 & 22.93 & 22.21 & 0.73 & 74.86 & 0.15 \\
\hline
\end{tabular}

Note: $R_{\mathrm{s}}$, solar radiation; $R_{n}$, net radiation; $T_{a}$, air temperature; $T_{s}$, surface temperature; $V P D$, water vapor pressure deficit; $R H$, relative humidity; $u$, wind speed.

\section{Models}

\subsection{Penman-Monteith model}

The Penman-Monteith (PM) model for estimating ET is described as follows (Monteith, 1965):

$$
\lambda E T=\frac{\Delta\left(R_{n}-G\right)+\rho C_{P} V P D / r_{a}}{\Delta+\gamma\left(1+r_{s} / r_{a}\right)},
$$

where, $\lambda$ is the latent heat of water vaporization $(\mathrm{J} / \mathrm{kg}) ; E T$, the evapotranspiration rate; $\Delta$, the slope of saturation water vapor pressure-temperature curve $(\mathrm{kPa} / \mathrm{K}) ; R_{n}$, the net radiation $\left(\mathrm{W} / \mathrm{m}^{2}\right)$; $G$, soil heat flux $\left(\mathrm{W} / \mathrm{m}^{2}\right) ; C_{p}$, the specific heat of dry air at a constant pressure $(\mathrm{J} /(\mathrm{kg} \cdot \mathrm{K})) ; \rho$, the air density $\left(\mathrm{kg} / \mathrm{m}^{3}\right) ; V P D$, the water vapor pressure deficit $(\mathrm{KPa}) ; r_{a}$, the aerodynamic resistance $(\mathrm{s} / \mathrm{m}) ; \gamma$, the psychometric constant $(\mathrm{KPa} / \mathrm{K})$; and $r_{s}$, the surface resistance $(\mathrm{s} / \mathrm{m})$.

\subsection{Surface resistance model}

We developed a surface resistance model according to the resistance law of fluid transmission, canopy resistance, and soil resistance. From the principle of parallel electric circuit, the model can 
be described as follows:

$$
r_{s-D E}=\frac{1}{a L A I / r_{s}^{c}+b / r_{s}^{s}},
$$

where, $r_{s-D E}$ is the developed surface resistance $(\mathrm{s} / \mathrm{m}) ; r_{s}^{c}$, the canopy resistance $(\mathrm{s} / \mathrm{m}) ; r_{s}^{s}$, the soil resistance ( $\mathrm{s} / \mathrm{m}) ; L A I$, the leaf area index; and $a$ and $b$ are the empirical coefficients which can be obtained by least-square fitting of the measurements from the weighing lysimeter in 2016. In our study, the values of $a$ and $b$ were 1.52 and 0.05 , respectively, and the canopy resistance was estimated by the stomatal resistance as follows:

$$
r_{\mathrm{s}}^{c}=\frac{r_{s T}}{L A I_{e}},
$$

where, $r_{S T}$ is the stomatal resistance $(\mathrm{s} / \mathrm{m})$ and can be obtained from its relationship with the solar radiation. The effective leaf area index, $L A I_{e}$, can be set as follows: $L A I_{e}$ equals to $L A I$ when $L A I \leq 2$, equals to 2 when $2<L A I<4$, and equals to $L A I / 2$ when $L A I \geq 4$ (Gardiol et al., 2003).

The soil resistance $\left(r_{s}^{s}\right)$ was calculated using the Anadranistakis model as follows (Anadranistakis et al., 2000):

$$
r_{s}^{s}=r_{s \min }^{s} f\left(\theta_{s}\right)=r_{s \min }^{s}\left(2.5 \frac{\theta_{F}}{\theta_{s}}-1.5\right),
$$

where, $r_{s \text { min }}^{s}$ is the minimum soil resistance when soil water content is at field capacity, taken as $100 \mathrm{~s} / \mathrm{m}$ in this paper (Camillo and Gurney, 1986); $\theta_{F}$, the field capacity for soil in depth of 0-10 $\mathrm{cm}$; and $\theta_{s}$, the soil water content in depth of $0-10 \mathrm{~cm}$.

\subsection{Aerodynamic resistance models}

The aerodynamic resistance was calculated by three methods. The first one is from Perrier (1975a, b) and can be described as follows:

$$
r_{a 1}=\frac{\ln \left[(x-d) /\left(h_{c}-d\right)\right] \ln \left[(x-d) / z_{0}\right]}{k^{2} u},
$$

where, $k$ is the Karman constant $(0.40) ; x$, the reference height $(2 \mathrm{~m}) ; h_{c}$, the mean crop height (m); $d$, the zero plane displacement $(\mathrm{m}) ; u$, the wind speed at the reference height $(\mathrm{m} / \mathrm{s}) ;$ and $z_{0}$, the roughness length of the crop relative to momentum transfer $(\mathrm{m})$. The $z_{0}$ and $d$ are defined as functions of crop height and $L A I$ (Brenner and Incoll, 1997) as follows:<

$$
\begin{gathered}
d=1.1 h_{c} \ln \left(1+X^{0.25}\right), \\
z_{0}=\left\{\begin{array}{ll}
z_{0}{ }^{\prime}+0.3 h_{c} X^{0.5} & 0<X<0.2 \\
0.3 h_{c}\left(1-d / h_{c}\right) & 0.2<X<1.5
\end{array},\right.
\end{gathered}
$$

where, $X=c_{d} \times L A I$ with $c_{d}$ being the mean drag coefficient and taken as 0.07 (Brenner and Incoll, $1997)$, and $z_{0}^{\prime}$ is the roughness length of bare soil surface $(0.01 \mathrm{~m})$ (Shuttleworth and Wallace, 1985).

Considering that wind speed in solar greenhouse is generally small under natural ventilation and that the aerodynamic resistance could become infinite when wind speed is close to zero, the second method for calculating the aerodynamic resistance from the formula of Thom and Oliver (1977) is adopted:

$$
r_{a 2}=4.72\left[\ln \left(\frac{x-d}{z_{0}}\right)\right]^{2} /(1+0.54 u) .
$$

When wind speed is negligible, $r_{\mathrm{a} 2}$ reduces to

$$
r_{a 2}=4.72\left[\ln \left(\frac{x-d}{z_{0}}\right)\right]^{2} .
$$

The above methods were also used by Chen et al. (2007) and Liu et al. (2011) to calculate the aerodynamic resistance in solar greenhouse. 
Since eddy diffusion can transport both air and water vapor, the aerodynamic resistance $\left(r_{\mathrm{a} 3}\right)$ calculated method is to use the convective heat transfer coefficient for individual leaf as follows (Zhang and Lemeur, 1992):

$$
r_{a 3}=\frac{\rho c_{p}}{2 h L A I},
$$

where, $h$ is the convective heat transfer coefficient $\left(\mathrm{W} /\left(\mathrm{m}^{2} \cdot \mathrm{K}\right)\right)$. Qiu et al. (2013) showed that the convection in greenhouses was dominated by mixed convection during daytime and $h$ can hence be calculated as follows (Stanghellini, 1993):

$$
h=0.37\left(\frac{k_{c}}{d_{c}}\right)\left(G_{r}+0.692 R_{e}^{2}\right)^{1 / 4},
$$

where, $k_{c}$ is the thermal conductivity of air $(\mathrm{W} /(\mathrm{m} \cdot \mathrm{K})) ; d_{c}$, the characteristic dimension of the leaf (m); $G_{r}$, the Grashof number; and $R_{e}$, the Reynolds number. $d_{c}$ can be calculated as follows (Montero et al., 2001):

$$
d_{c}=\frac{2}{1 / L+1 / W},
$$

where, $L$ is the leaf length (m) and $W$ is the leaf width (m). The $G_{r}$ and $R_{e}$ in Equation 13 can be calculated as follows (Bailey et al., 1993):

$$
\begin{gathered}
G_{r}=\frac{\beta g d_{c}^{3}\left[T_{s}-T_{a}\right]}{v^{2}}, \\
R_{e}=\frac{u d_{c}}{v},
\end{gathered}
$$

where, $\beta$ is the thermal expansion coefficient of air (taken as $3.315 \times 10^{-3} / \mathrm{K}$ ); $g$, the gravity acceleration $\left(\mathrm{m} / \mathrm{s}^{2}\right)$; and $v$, the kinematic viscosity of air (taken as $16.4 \times 10^{-6} \mathrm{~m}^{2} / \mathrm{s}$ ).

\subsection{Evaluation of the models}

The accuracy of the models was quantified by the coefficient of determination $\left(R^{2}\right)$. The mean absolute error $(M A E)$, the root mean square error $(R M S E)$ and the index of agreement $\left(d_{l}\right)$ can be expressed as follows (Mayer and Butler, 1993):

$$
\begin{gathered}
R^{2}=\left\{\frac{\sum_{i=1}^{n}\left(Q_{i}-\bar{Q}\right)\left(P_{i}-\bar{P}\right)}{\left.\sqrt{\left(Q_{i}-\bar{Q}\right)^{2}} \sqrt{\left(P_{i}-\bar{P}\right)^{2}}\right\},}\right. \\
M A E=\sum_{i=1}^{n}\left|Q_{i}-P_{i}\right| / n, \\
R M S E=\left[\sum_{i=1}^{n}\left|Q_{i}-P_{i}\right|^{2} / n\right]^{0.5}, \\
d_{l}=1-\frac{\sum_{i=1}^{n}\left(Q_{i}-P_{i}\right)^{2}}{\sum_{i=1}^{n}\left(\left|P_{i}-\bar{Q}\right|+\left|Q_{i}-\bar{Q}\right|\right)^{2}},
\end{gathered}
$$

where, $P_{i}$ and $Q_{i}$ are the calculated and measured values, respectively; $\bar{Q}$, the mean of the measurements; $\bar{P}$, the mean of the calculations; and $n$, the number of measurements.

\section{Results}

\subsection{Diurnal variations of meteorological factors}

The diurnal variations of $T_{a}, T_{s}, T_{s}-T_{a}, R n, V P D, R H$, and $u$ in a typical sky-clear day (20 May, 
2015) and a cloudy day (29 May, 2015) are shown in Figure 1. There was no remarkable difference between $T_{s}$ and $T_{a}$ before 09:00 in the sky-clear day and before 11:00 in the cloudy day. During the rest time of the same day, $T_{s}$ was consistently lower than $T_{\mathrm{a}}$ (Fig. 1a). The mean maximum difference between $T_{s}$ and $T_{a}$ occurred around 14:00, reaching $6{ }^{\circ} \mathrm{C}$ in the sky-clear day and $2.3^{\circ} \mathrm{C}$ in the cloudy day, due to high transpiration rate. Plants associated with elevated $V P D$ and radiation make their leaves cooler than the ambient air (Rouphael and Colla, 2004; Liu and Fan, 2012).

The diurnal variations of $R_{n}$ and $V P D$ were similar (Fig. 1b). The $R_{n}$ and $V P D$ peaked around 14:00 in the sky-clear day, reaching $554.2 \mathrm{~W} / \mathrm{m}^{2}$ and $2.6 \mathrm{kPa}$, respectively, while in the cloudy day they peaked at $11: 30$, reaching $224.2 \mathrm{~W} / \mathrm{m}^{2}$ and $0.8 \mathrm{kPa}$, respectively. The average of $R H$ in the sky-clear day is $56.1 \%$, lower than that in the cloudy day $(92.1 \%)$. Since a part of the vents in the greenhouse was switched off in night, it results in the $u$ in the daytime higher than that in the night (Fig. 1c).
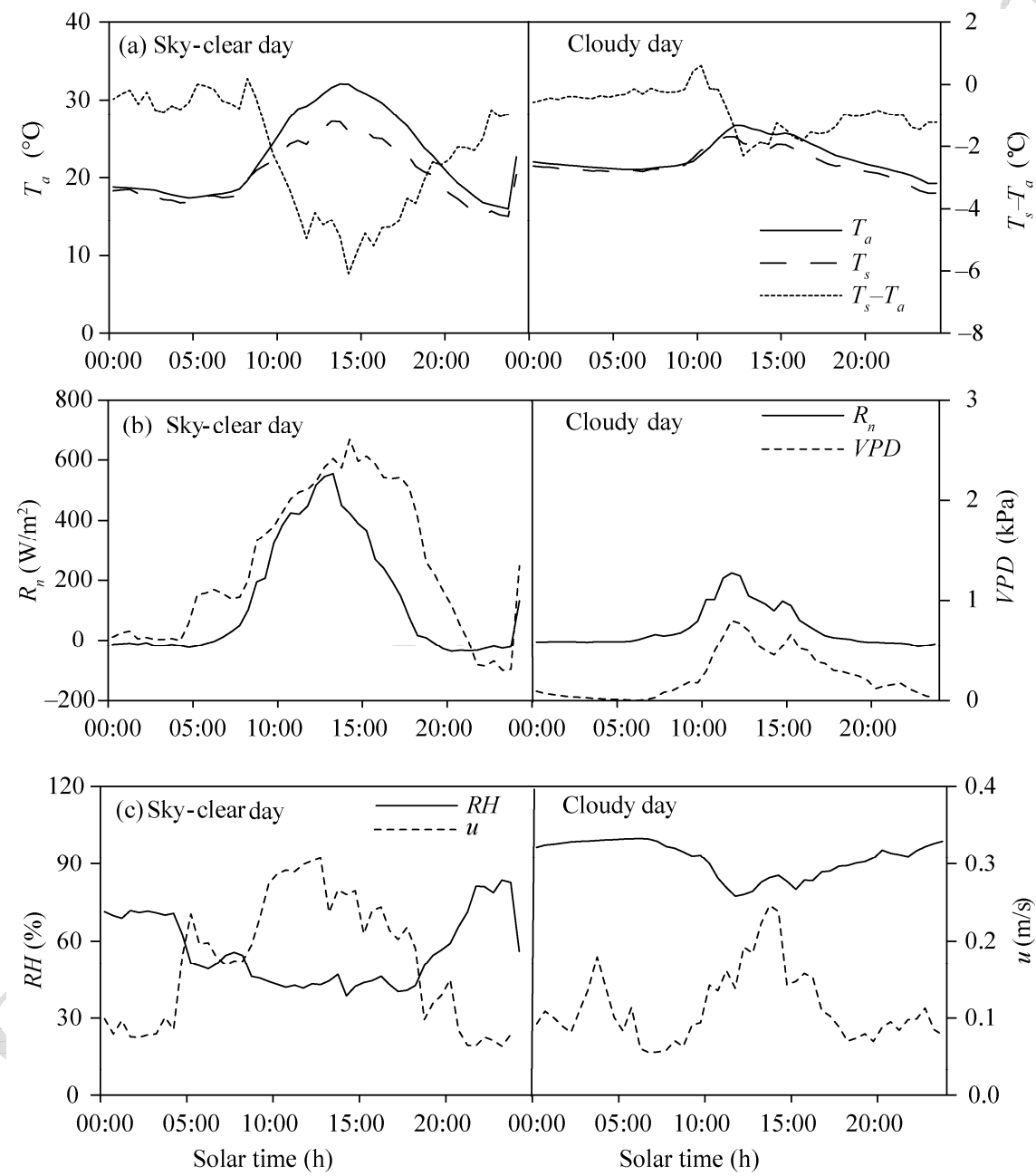

Fig. 1 Diurnal variations of air temperature $\left(T_{a}\right)$, surface temperature $\left(T_{s}\right)$, difference between canopy and air temperatures $\left(T_{s}-T_{a}\right)$, net radiation $\left(R_{n}\right)$, water vapor pressure deficit $(V P D)$, relative humidity $(R H)$ and wind speed $(u)$ measured in a typical sky-clear day (20 May, 2015) and a cloud day (29 May, 2015)

\subsection{Surface resistance model and canopy resistance model}

The stomatal resistance $\left(r_{s T}\right)$ is an important parameter for calculating canopy resistance $\left(r_{s}^{c}\right)$. Our statistical analysis revealed that the $r_{S T}$ was a function of $R_{S}$ during the daytime (Fig. 2). The relationship between $r_{S T}$ and $R_{S}$ can be fitted to an exponential function as follows: 


$$
r_{s T}=23.21 \exp \left(1021.06 /\left(R_{s}+365.71\right)\right) \text {. }
$$

The value of $R^{2}$ was 0.82 , with $M A E$ of $17.58 \mathrm{~s} / \mathrm{m}$ and $R M S E$ of $25.10 \mathrm{~s} / \mathrm{m}$. Therefore, the stomatal resistance of the tomato in the solar greenhouse can be accurately estimated from its relationship with $R_{S}$ in our study.

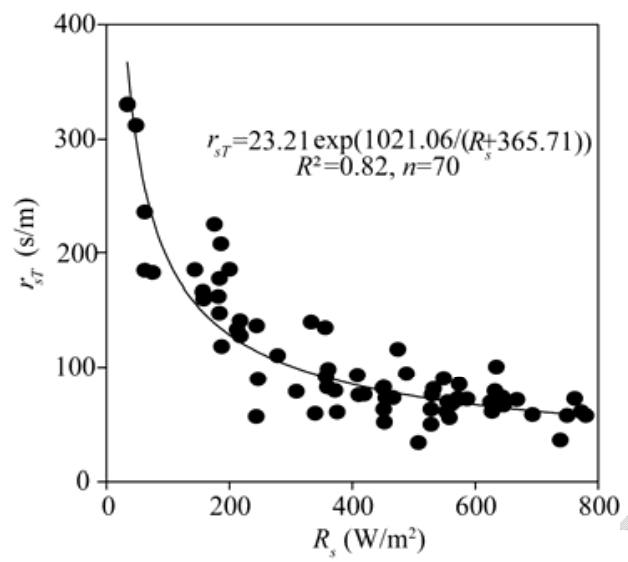

Fig. 2 An exponential relationship between leaf stomatal resistance $\left(r_{s T}\right)$ and solar radiation $\left(R_{s}\right)$

Figure 3 shows the seasonal variations of the $r_{s}^{c}, r_{s-D E}$ calculated by the proposed model, as well as $L A I$ during the experiments in 2015 and 2016. The $r_{s-D E}$ and $r_{s}^{c}$ decreased rapidly as $L A I$ increased during the seedling period, and the $r_{s-D E}$ was slightly higher than $r_{s}^{c}$, especially when the $L A I$ was less than 1.0. However, when the $L A I$ was higher than 1.0, the canopy gradually covered the soil surface and the soil surface resistance decreased as a result (the mean was less than $100 \mathrm{~s} / \mathrm{m}$ in our study), resulting in the $r_{s-D E}$ slightly lower than the $r_{s}^{c}$. When $L A I$ was lower than 1.0, the means of $r_{s-D E}$ and $r_{s}^{c}$ were 632.97 and $444.87 \mathrm{~s} / \mathrm{m}$, respectively in 2015 , and 738.37 and $555.72 \mathrm{~s} / \mathrm{m}$, respectively in 2016. When $L A I$ was higher than 1.0 , the means of $r_{s}^{c}$ were $72.3 \%$ and $68.2 \%$ higher than the means of the $r_{s-D E}$ in 2015 and 2016 , respectively.

\subsection{Seasonal variations of aerodynamic resistance calculated by the three methods}

In the solar greenhouse, the wind speed was small and the daily mean wind speed varied from 0.05 to $0.43 \mathrm{~m} / \mathrm{s}$ (see Table 1). Figure 4 shows the seasonal variations of the aerodynamic resistance $\left(r_{\mathrm{a} 1}, r_{\mathrm{a} 2}\right.$, and $\left.r_{\mathrm{a} 3}\right)$ calculated by the three models proposed by Perrier $(1975 \mathrm{a}, \mathrm{b})$, Thom and Oliver (1977) and Zhang and Lemeur (1992), respectively, during the experiments in 2015 and 2016. The variations of $r_{\mathrm{a} 1}, r_{\mathrm{a} 2}$, and $r_{\mathrm{a} 3}$ were comparable and they all peaked at the seedling stage and then decreased gradually. The value of $r_{\mathrm{a} 1}$ was consistently higher than those of $r_{\mathrm{a} 2}$ and $r_{\mathrm{a} 3}$ during the experiments, while the value of $r_{a 3}$ was higher than that of $r_{a 2}$, especially in the seedling stage. During the seedling stage, $r_{a 1}$ was mainly affected by wind speed and its value was higher than $800 \mathrm{~s} / \mathrm{m}$ when wind speed was below $0.1 \mathrm{~m} / \mathrm{s}$. The $r_{a 3}$ was remarkably higher than $r_{a 2}$ in the seedling stage, and the means of $r_{a 3}$ were $63.1 \%$ and $68.3 \%$ higher than the means of $r_{a 2}$ in 2015 and 2016, respectively.

\subsection{Comparison of the daily evapotranspiration}

Figure 5 shows the seasonal variations of the daily ET estimated by the developed surface resistance model and the canopy resistance model combined with the aerodynamic resistance calculated by the three methods. The results measured by the weighing lysimeter in 2016 were also plotted for comparison. It can be seen from Figure 5 that the combinations of PM- $r_{s}^{c}-r_{a 1}$, PM- $r_{s}^{c}-r_{a 2}$, and PM- $r_{s}^{c}-r_{a 3}$ underestimated the daily ET by $4.8 \%, 38.1 \%$ and $22.9 \%$, respectively during the entire experimental period. In contrast, the daily ET estimated using the PM- $r_{s-D E}-r_{a 3}$ was in good agreement with the measurements, while the PM- $r_{s-D E}-r_{a 1}$ and PM- $r_{s-D E^{-}} r_{a 2}$ 

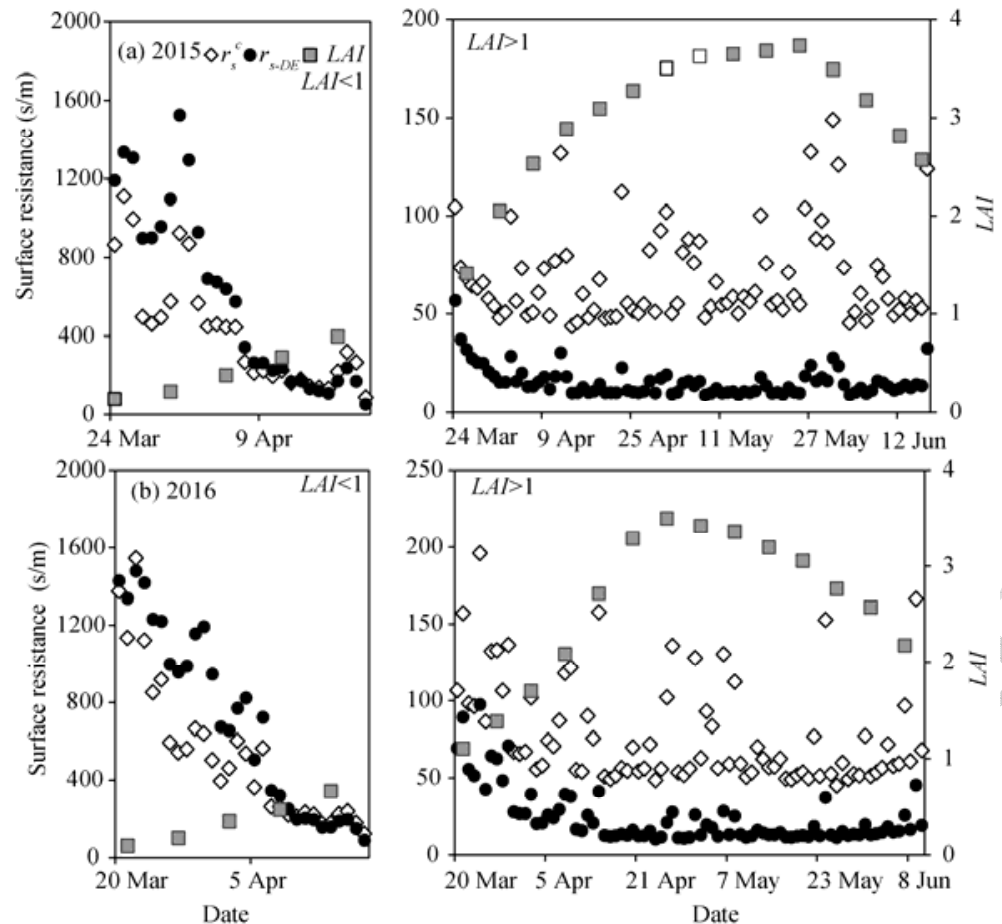

Fig. 3 Seasonal variations of the daily canopy resistance $\left(r_{s}^{c}\right)$, the surface resistance $\left(r_{s-D E}\right)$ calculated by the proposed model, and the leaf area index (LAI) in 2015 and 2016
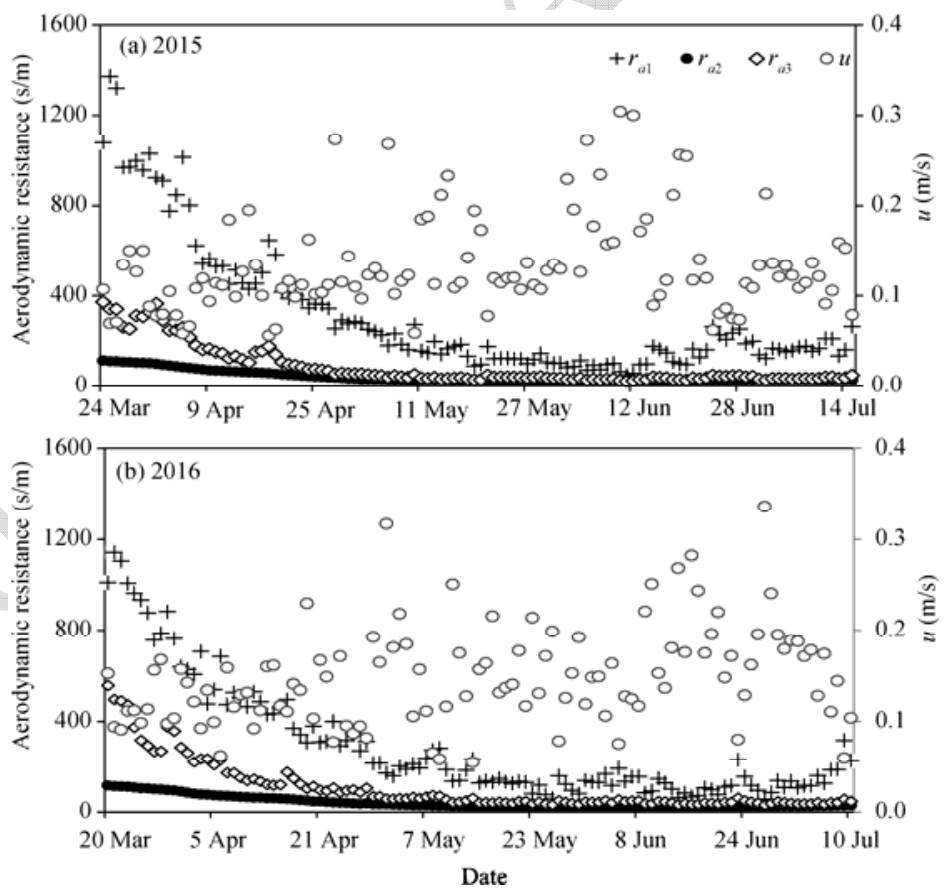

Fig. 4 Seasonal variations of the aerodynamic resistance calculated by the three methods in 2015 and 2016. $r_{a 1}$ from Perrier (1975a, b); $r_{a 2}$ from Thom and Oliver (1977); $r_{a 3}$ from Zhang and Lemeur (1992); $u$, wind speed.

combinations slightly overestimated and underestimated the daily ET by $5.2 \%$ and $9.6 \%$, respectively. To evaluate the performance of the $r_{S-D E}$ model in the seedling stage, we compared the diurnal variations of the hourly ET estimated by PM- $r_{s}^{c}-r_{a 3}$ and PM- $r_{s-D E}-r_{a 3}$ with the 
measured $E T$ from the weighing lysimeter $\left(E T_{W L}\right)$. Figure 6 shows that the $E T$ estimated by PM- $r_{s-D E^{-}} r_{a 3}$ was close to $E T_{W L}$, whereas the $E T$ estimated by PM- $r_{s}^{c}-r_{a 3}$ was higher than $E T_{W L}$, especially around lunch time, due to the difference between $r_{s-D E}$ and $r_{s}^{c}$ in treating the integrated influence of canopy and soil surface resistances as discussed above.
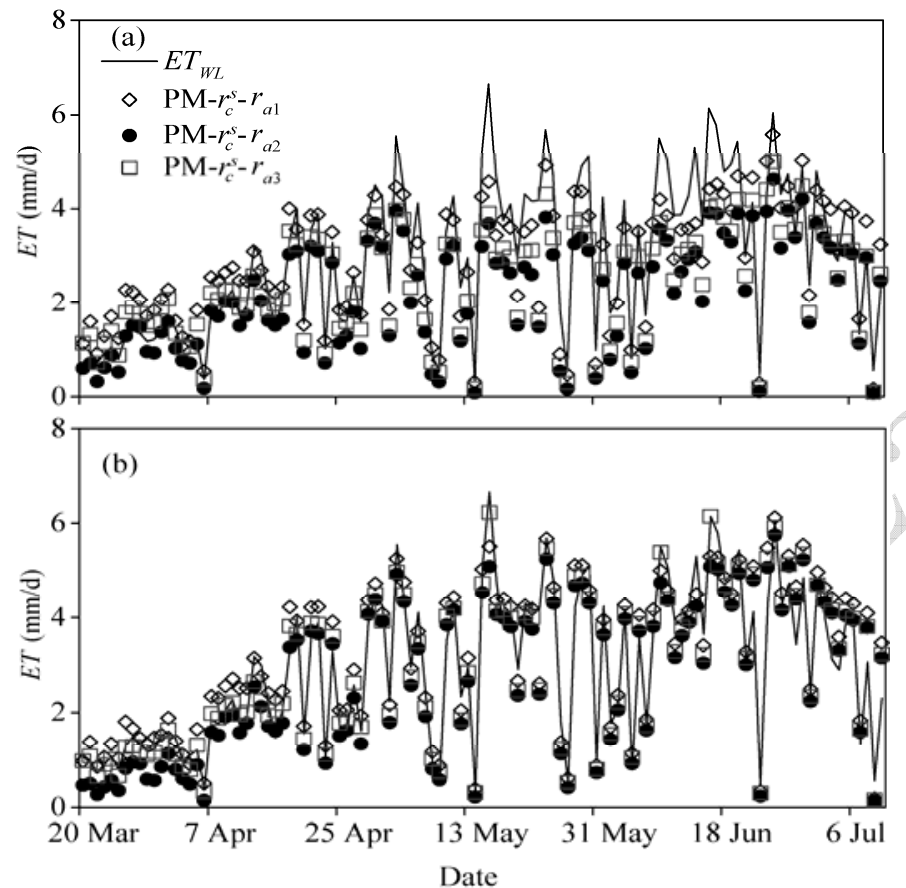

Fig. 5 Seasonal variations of the daily evapotranspiration $(E T)$ estimated by PM model in combination with different resistance models (a). The results measured from the weighing lysimeter $\left(E T_{W L}\right)$ in 2016 were also plotted for comparison (b).

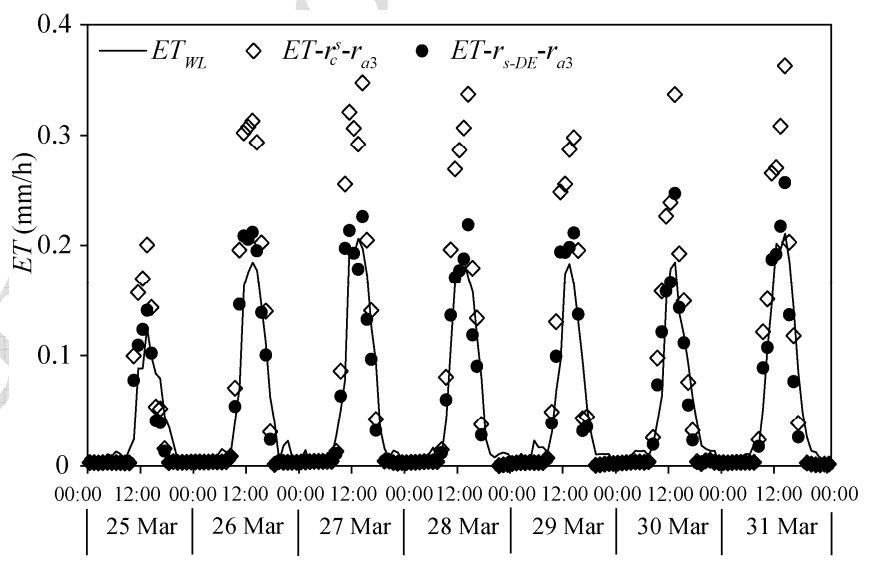

Fig. 6 Comparison between diurnal variations of the hourly evapotranspiration (ET) estimated by PM- $r_{s}^{c}-r_{a 3}$, $\mathrm{PM}-r_{s-D E^{-}} r_{a 3}$ and the results measured from the weighing lysimeter $\left(E T_{W L}\right)$ from 25 March to 31 March, 2016

Figure 7 and Table 2 compare the daily ET estimated by the PM model using different resistance models and the measurements from the sap flow system combined with the micro-lysimeter in 2015 and with the weighing lysimeter in 2016. Table 2 reveals that the $r_{s}^{c}$ model in combination with $r_{a 1}, r_{a 2}$, and $r_{a 3}$ underestimated the daily ET in the two years, with a slope of $0.86,0.68$, and 0.73 , respectively. The $r_{s-D E}$ model in combination with $r_{a 2}$ underestimated the daily ET by $10.5 \%$ in the two years, with the slope, MAE and RMSE being 
$0.90,0.46 \mathrm{~mm} / \mathrm{d}$ and $0.60 \mathrm{~mm} / \mathrm{d}$, respectively. The $r_{s-D E}$ model in combination with $r_{a 1}$ and $r_{a 3}$ works better: the slope being 0.98 (for $r_{a 1}$ ) and 0.96 (for $r_{a 3}$ ), $M A E$ being 0.40 and $0.34 \mathrm{~mm} / \mathrm{d}$, and $R M S E$ being 0.55 and $0.45 \mathrm{~mm} / \mathrm{d}$. However, the determination coefficient of $r_{a 3}$ was superior to $r_{a 1}$. These indicated that combining the aerodynamic resistance calculated from the eddy diffusion theory with the developed surface resistance can improve the PM model in estimating the daily $E T$ of tomato in the solar greenhouse.

\subsection{Performance of the proposed surface resistance model during irrigation}

Irrigation temporally alters the water transfer in soil and crop and soil evaporation increase steadily after irrigation simply due to the readily availability of evaporative water. We then investigated the effect of irrigation on the proposed surface resistance model.

Figure 8 shows the variations of the ET estimated by the proposed surface resistance model in comparison with the measurements from the weighing lysimeter during the thirteen irrigation events (except irrigation at seedling stage) in 2016. It is evident that the results estimated from the
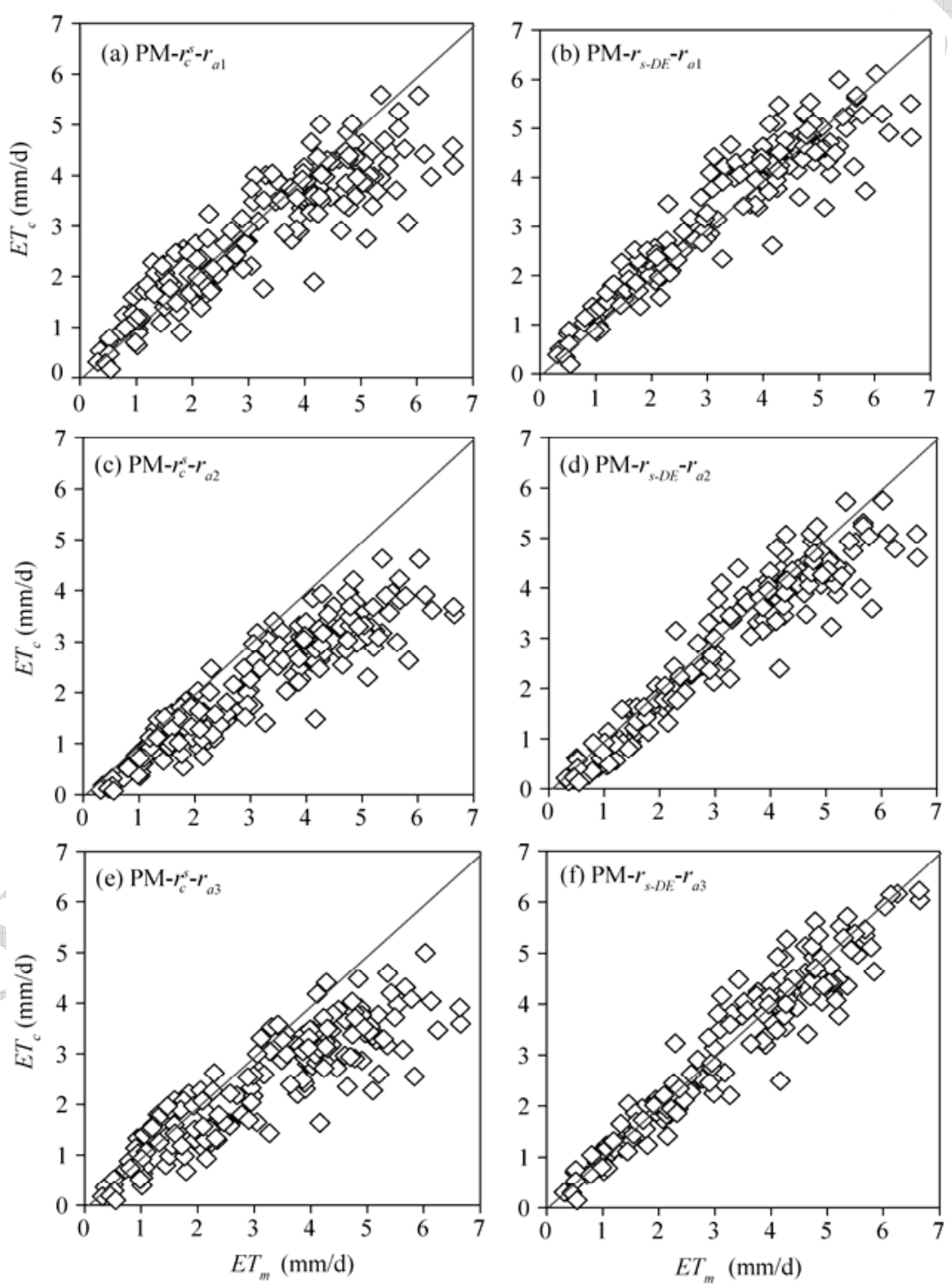

Fig. 7 Comparison between the daily evapotranspiration (ET) estimated by the PM model using different resistance models $\left(E T_{c}\right)$ and the results measured from the sap flow system combined with the micro-lysimeter and with the weighing lysimeter $\left(E T_{m}\right)$ in 2015 and 2016 
Table 2 Comparing the daily evapotranspirations estimated by the proposed surface model and the canopy resistance model, using the three aerodynamic resistance methods, with the results measured from the sap flow system combined with the micro-lysimeter and with the weighing lysimeter in 2015 and 2016

\begin{tabular}{cclccccccc}
\hline $\begin{array}{c}\text { Surface } \\
\text { resistance }\end{array}$ & $\begin{array}{c}\text { Aerodynamic } \\
\text { resistance }\end{array}$ & Regression equation & $R^{2}$ & $\begin{array}{c}M A E \\
(\mathrm{~mm} / \mathrm{d})\end{array}$ & $\begin{array}{c}R M S E \\
(\mathrm{~mm} / \mathrm{d})\end{array}$ & $d_{l}$ & $\begin{array}{c}\bar{Q} \\
(\mathrm{~mm} / \mathrm{d})\end{array}$ & $\begin{array}{c}\bar{P} \\
(\mathrm{~mm} / \mathrm{d})\end{array}$ & $\begin{array}{c}N \\
r_{s}^{c}\end{array}$ \\
$r_{\mathrm{a} 1}$ & $E T_{c}=0.86 E T_{m}$ & 0.76 & 0.59 & 0.79 & 0.92 & 3.24 & 2.91 & 175 \\
& $r_{\mathrm{a} 2}$ & $E T_{c}=0.68 E T_{m}$ & 0.85 & 1.02 & 1.23 & 0.83 & 3.24 & 2.23 & 175 \\
& $r_{\mathrm{a} 3}$ & $E T_{c}=0.73 E T_{m}$ & 0.77 & 0.89 & 1.13 & 0.84 & 3.24 & 2.43 & 175 \\
& $r_{\mathrm{a} 1}$ & $E T_{c}=0.98 E T_{m}$ & 0.86 & 0.40 & 0.55 & 0.97 & 3.24 & 3.26 & 175 \\
$r_{\mathrm{s}-D E}$ & $r_{\mathrm{a} 2}$ & $E T_{c}=0.90 E T_{m}$ & 0.90 & 0.46 & 0.60 & 0.96 & 3.24 & 2.90 & 175 \\
& $r_{\mathrm{a} 3}$ & $E T_{c}=0.96 E T_{m}$ & 0.92 & 0.34 & 0.45 & 0.98 & 3.24 & 3.12 & 175 \\
\hline
\end{tabular}

Note: $E T_{c}$ is the daily evapotranspiration estimated by the proposed surface model and the canopy resistance model using the three aerodynamic resistance methods, and $E T_{m}$ is the measurements from the sap flow system combined with the micro-lysimeter and the weighing lysimeter. $r_{s}^{c}$, the canopy resistance; $r_{\mathrm{s}-D E}$, surface resistance; $M A E$, mean absolute error; $R M S E$, root mean square error; $d_{l}$, index of agreement; $\bar{Q}$, mean of the measurements; $\bar{P}$, mean of the calculations; $N$, sampling numbers.

proposed surface resistance model are in good agreement with the measurements, especially after the irrigation. In the day of the irrigation, the maximum relative error of the daily ET estimated by the proposed surface resistance model is up to $40.4 \%$, with the $M A E$ varying between 0.07 and $1.69 \mathrm{~mm} / \mathrm{d}$. However, one day after the irrigation the maximum relative error reduced to $11.9 \%$, with $M A E$ varying between 0.01 and $0.59 \mathrm{~mm} / \mathrm{d}$. Two and three days after the irrigation, the proposed surface resistance model works equally well with its maximum relative error being less than $12.5 \%$ and $M A E$ being less than $0.63 \mathrm{~mm} / \mathrm{d}$.
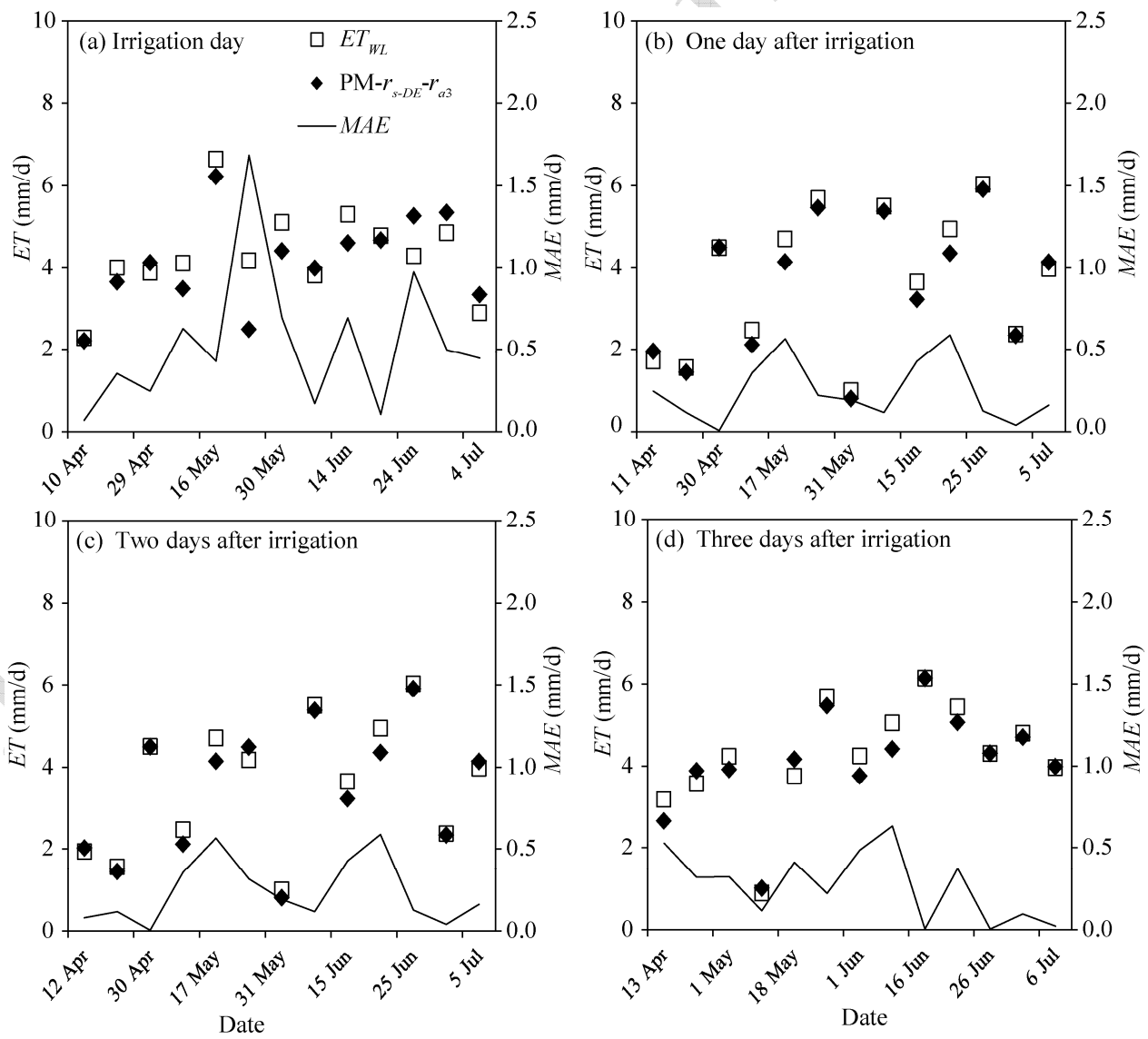

Fig. 8 Comparison between the evapotranspiration estimated by the proposed surface resistance model and the measurements from the weighing lysimeter during the 13 irrigation events in 2016. MAE, mean absolute error. 


\section{Discussion}

\subsection{Canopy resistance model and the proposed surface resistance model}

The leaf stomatal resistance is an important parameter to calculate canopy resistance and depends on a number of environmental factors. Stanghellini (1987) showed that the stomatal resistance of tomatoes was affected by $R_{s}, V P D, T_{a}$, and $\mathrm{CO}_{2}$ concentration. However, Jolliet and Bailey (1992) found that only the first two factors (i.e., $R_{s}, V P D$ ) were significant. Statistical analysis in our study showed that the stomatal resistance primarily depends on solar radiation during the daytime, and that an exponential relationship was found between the resistance and the radiation (Fig. 2). Similar results were also found for cucumber (Yang et al., 1990), waringin (Zhang and Lemeur, 1992), zucchini (Rouphael and Colla, 2004), geranium (Montero et al., 2001) and tomato (Qiu et al., 2013). The developed surface resistance model is superior to the canopy resistance model, especially when the $L A I$ is low or during irrigation period, because the developed surface resistance model considered the combined effect of crop and soil on water vapor transfer. Soil evaporation is dominant when $L A I$ is low and could increase steadily after irrigation. Because the canopy resistance model does not explicitly account for the water transfer in soil, using it in the PM model underestimates the ET. In contrast, the proposed model accounts for the soil surface resistance and hence improve the accuracy of the PM model. This is consistent with many other studies. For example, Stannard (1993) found that the PM model substantially underestimated the ET when the canopy resistance was significantly greater than the soil resistance. It was also found that when the canopy coverage ratio is low, using the canopy resistance in the PM model underestimated ET (Kato et al. 2004). It needs to point out that there were also studies showing that using the canopy resistance in the PM model could overestimate ET (Zhang et al., 2008; Li et al., 2014). Such controversial results are likely to be caused by changes in canopy resistance and/or soil water in root zones. For instance, with furrow irrigation or border irrigation, irrigation

is less frequent and the soil resistance increases as result (approximately $800 \mathrm{~s} / \mathrm{m}$ in dry soils). Consequently, the canopy resistance could reach $300 \mathrm{~s} / \mathrm{m}$ in daytime as the soil dried (Zhang et al., 2008). These could combine to give rise to an overestimated ET when using the canopy resistance model.

It is worth mentioning the $r_{s-D E}$ model is semi-empirical and needs calibration against experimental data. Also, its application to water-stress conditions requires verification. Therefore, the $r_{S-D E}$ model needs further investigation.

\subsection{Aerodynamic resistances calculated by the three models}

The aerodynamic resistances calculated by three models proposed by Perrier (1975a, b), Thom and Oliver (1977) and Zhang and Lemeur (1992) were compared. The $r_{\mathrm{a} 1}$ and $r_{\mathrm{a} 3}$ methods were superior and can adequately estimate the $E T$ of tomatoes in the solar greenhouse, whereas the $r_{\mathrm{a} 2}$ method underestimated the ET. However, the applicability of the $r_{\mathrm{a} 1}$ method to greenhouse was questioned (Qiu et al., 2013) because small wind speeds within the greenhouse could result in a spurious high aerodynamic resistance. However, Möller et al. (2004) showed that $r_{\mathrm{a} 1}$ works well in an insect-proof greenhouse and that the water vapor transfer depended on kinetic energy of wind. Villarreal-Guerrero et al. (2012) found that the predicted ET was insensitive to the external crop resistance, and the aerodynamic resistance can be taken as a constant at $70 \mathrm{~s} / \mathrm{m}$ in greenhouse. Similar findings were also reported in other studies (Kittas et al., 1999; Prenger et al., 2002). For the Stanghellini (1987) model, the average aerodynamic resistance was found to be $185 \mathrm{~s} / \mathrm{m}$ for tomatoes. Fernández et al. $(2010,2011)$ found that the FAO-56 PM model using constant aerodynamic resistance of $295 \mathrm{~s} / \mathrm{m}$ accurately estimated the daily reference evapotranspiration in greenhouse. In general, the aerodynamic resistances of crops in greenhouse oscillate between 100 and $500 \mathrm{~s} / \mathrm{m}$ (Bailey et al., 1993; Baille et al. 1994; Katsoulas et al. 2001). In our study, the average $r_{\mathrm{a} 1}$ was $308 \mathrm{~s} / \mathrm{m}$ and was obtained from the crop and meteorological data in 2015. Figure 9 compares the daily ET estimated through replacing $r_{\mathrm{a} 1}$ by $308 \mathrm{~s} / \mathrm{m}$ in the PM model with the measurement from the weighing lysimeter in 2016. The results estimated by the proposed surface resistance model were in good agreement with the measurements, with $M A E$ and $R M S E$ being 
0.43 and $0.56 \mathrm{~mm} / \mathrm{d}$, respectively, slightly higher than the PM- $r_{s-D E^{-}} r_{a 3}$ method (MAE and RMSE being 0.34 and $0.45 \mathrm{~mm} / \mathrm{d}$, respectively). The convection theory is generally used to calculate the aerodynamic resistance in greenhouse where the transfer of sensible heat between canopy and the atmosphere is through convection because the wind speed is small (Zhang and Lemeur, 1992). Qiu et al. (2013) found that the PM model can accurately estimate the transpiration of hot pepper in solar greenhouse under mixed convection condition. There were also studies showing that the PM model can accurately estimate the transpirations of crops grown in different types of greenhouses when the convection is free (McAdams, 1954) or forced (Gröber and Erk, 1961). However, these studies were conducted in temperate or maritime climate in Europe and Mediterranean, which differ from northern China in terms of environmental factors.
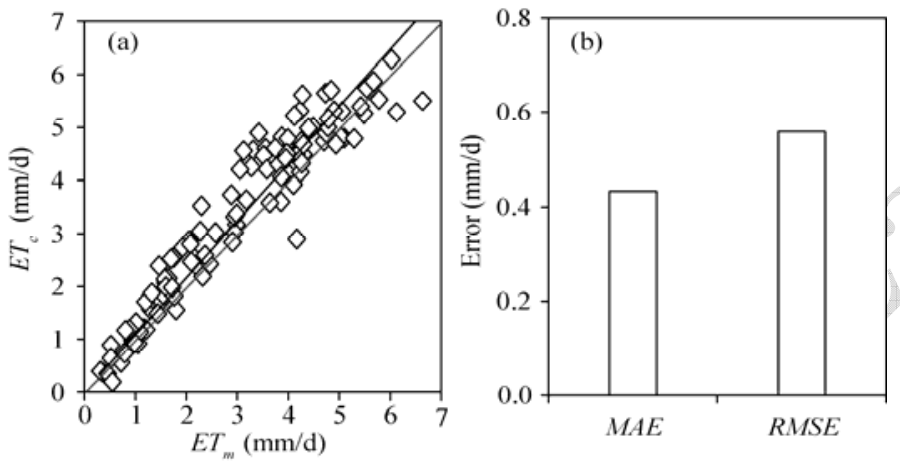

Fig. 9 Comparison between the evapotranspiration $(E T)$ estimated by the PM- $r_{s-D E^{-}} r_{a 1} \operatorname{method}\left(r_{a 1}=308 \mathrm{~s} / \mathrm{m}\right)$ $\left(E T_{c}\right)$ and the measurements from the weighing lysimeter $\left(E T_{m}\right)$ in $2016(\mathrm{a})$, as well as its errors (b). $M A E$, mean absolute error; RMSE, root mean square error.

As discussed above, the PM formula can estimate the ET of tomato in solar greenhouse when the $L A I$ is low or during irrigation using the developed surface resistance model with the aerodynamic resistance calculated by mixed convection theory. A good relationship between the simulated and measured $E T$ was found with $M A E, R M S E$ and $d_{l}$ being $0.34 \mathrm{~mm} / \mathrm{d}, 0.45 \mathrm{~mm} / \mathrm{d}$, and 0.98, respectively (Fig. $7 \mathrm{f}$ and Table 2). Also, when the canopy temperature cannot be measured in greenhouse, it is acceptable to calculate the ET by setting the aerodynamic resistance as a constant of $308 \mathrm{~s} / \mathrm{m}$.

\section{Conclusions}

This paper proposed a surface resistance model by combining the restrictions of soil and vegetation to water vapor transfer to estimate the $E T$ of tomato in solar greenhouse, especially under a condition of the $L A I$ being below 1.0. This provides an effective method to calculate the surface resistance for the Penman-Monteith model to estimate the ET when crop canopy is spatially sparse. In solar greenhouse, the aerodynamic resistance can be calculated using the mixed convection theory or taken as $308 \mathrm{~s} / \mathrm{m}$ as a constant parameter. Our results show that the PM formula improves the estimation of ET in comparison with other models when using the proposed surface resistance model with the aerodynamic resistance calculated by the mixed convection theory. Meanwhile, the proposed model also works well during irrigation period, especially a few days after the irrigation.

\section{Acknowledgements}

The study was funded by the Science and Technology Innovation Project of Chinese Academy of Agricultural Sciences (FIRI2016-07).

\section{References}

Allen R G, Pereira L S, Raes D, et al. 1998. Crop Evapotranspiration: Guidelines for Computing Crop Water Requirements. 
FAO Irrigation and Drainage Paper 56, Rome, Italy: FAO.

Anadranistakis M, Liakatas A, Kerkides P, et al. 2000. Crop water requirements model tested for crops grown in Greece. Agricultural Water Management, 45(3): 297-316.

Bailey B J, Montero J I, Biel C, et al. 1993. Transpiration of Ficus benjamina: comparison of measurements with predictions of the Penman-Monteith model and a simplified version. Agricultural and Forest Meteorology, 65(3-4): 229-243.

Baille M, Baille A, Delmon D. 1994. Microclimate and transpiration of greenhouse rose crops. Agricultural and Forest Meteorology, 71(1-2): 83-97.

Brenner A J, Incoll L D. 1997. The effect of clumping and stomatal response on evaporation from sparsely vegetated shrublands. Agricultural and Forest Meteorology, 84(3): 187-205.

Camillo P J, Gurney R. 1986. A resistance parameter for bare-soil evaporation models. Soil Science, 141(2): 95-105.

Chen X M, Cai H J, Li H X, et al. 2007. Calculation and verification of crop evapotranspiration in greenhouse. Advances in Water Science, 18(6): 812-815. (in Chinese)

Fernández M D, Bonachela S, Orgaz F, et al. 2010. Measurement and estimation of plastic greenhouse reference evapotranspiration in a Mediterranean climate. Irrigation Science, 28(6): 497-509.

Fernández M D, Bonachela S, Orgaz F, et al. 2011. Erratum to: Measurement and estimation of plastic greenhouse reference evapotranspiration in a Mediterranean climate. Irrigation Science, 29(1): 91-92.

Gao Y, Duan A W, Qiu X Q, et al. 2013. Modeling evapotranspiration in maize/soybean strip intercropping system with the evaporation and radiation interception by neighboring species model. Agricultural Water Management, 128: 110-119.

Guo W Z, Chen Q Y, Gao L H, et al. 2005. Present situation and developmental tendency on system of water saving irrigation of vegetable production in protective cultivation. Transactions of the CSAE, 21 (Suppl.): 24-27. (in Chinese)

Gardiol J M, Serio L A, Della Maggiora A I. 2003. Modelling evapotranspiration of corn (Zea mays) under different plant densities. Journal of Hydrology, 271(1-4): 188-196.

Gröber H, Erk S. 1961. Fundamentals of heat transfer ( $3^{\text {rd }}$ ed.). New York: McGraw-Hill, 288.

Ham J M, Heilman J L, Lascano R J. 1990. Determination of soil water evaporation and transpiration from energy balance and stem flow measurements. Agricultural and Forest Meteorology, 52(3-4): 287-301.

Iritz Z, Lindroth A, Heikinheimo M, et al. 1999. Test of a modified Shuttleworth-Wallace estimate of boreal forest evaporation. Agricultural and Forest Meteorology, 98-99: 605-619.

Jolliet O, Bailey B J. 1992. The effect of climate on tomato transpiration in greenhouses: measurements and models comparison. Agricultural and Forest Meteorology, 58(12): 43-62.

Juhász Á, Hrotkó K. 2014. Comparison of the transpiration part of two sources evapotranspiration model and the measurements of sap flow in the estimation of the transpiration of sweet cherry orchards. Agricultural Water Management, 143: 142-150.

Kato T, Kimura R, Kamichika M. 2004. Estimation of evapotranspiration, transpiration ratio and water-use efficiency from a sparse canopy using a compartment model. Agricultural Water Management, 65(3): 173-191.

Katsoulas N, Baille A, Kittas C. 2001. Effect of misting on transpiration and conductances of a greenhouse rose canopy. Agricultural and Forest Meteorology, 106(3): 233-247.

Kittas C, Katsoulas N, Baille A. 1999. Transpiration and canopy resistance of greenhouse soilless roses: measurements and modeling. Acta horticulturae. 507: 61-68.

Li S E, Hao X M, Du T S, et al. 2014. A coupled surface resistance model to estimate crop evapotranspiration in arid region of northwest China. Hydrological Processes, 28(4): 2312-2323.

Li S E, Zhang L, Kang S Z, et al. 2015. Comparison of several surface resistance models for estimating crop evapotranspiration over the entire growing season in arid regions. Agricultural and Forest Meteorology, 208: 1-15.

Liu H, Sun J S, Duan A W, et al. 2009. Experiment on soil evaporation of radish in sunlight greenhouse. Transactions of the CSAE, 25(1): 176-180. (in Chinese)

Liu C, Fan X K. 2012. Diagnosis of soil moisture in greenhouse based on canopy leaf-air temperature difference. Agricultural Research in the Arid Areas, 30(1): 90-93. (in Chinese)

Liu H, Duan A W, Li F S, et al. 2013. Drip irrigation scheduling for tomato grown in solar greenhouse based on pan evaporation in North China Plain. Journal of Integrative Agriculture, 12(3): 520-531.

Liu H, Duan A W, Sun J S, et al. 2011. Estimating model of transpiration for greenhouse tomato based on Penman-Monteith equation. Transactions of the CSAE, 27(9): 208-213. (in Chinese)

Mayer D G, Butler D G. 1993. Statistical validation. Ecological Modelling, 68(1-2): 21-32.

McAdams W H. 1954. Heat transmission ( ${ }^{\text {rd }}$ ed.). New York: McGraw-Hill, 442.

Monteith J L. 1965. Evaporation and environment. Symposia of the Society for Experimental Biology, 19: $205-234$.

Montero J I, Antón A, Muûoz P, et al. 2001. Transpiration from geranium grown under high temperatures and low humidities in 
greenhouses. Agricultural and Forest Meteorology, 107(4): 323-332.

Möller M, Tanny J, Li Y, et al. 2004. Measuring and predicting evapotranspiration in an insect-proof screenhouse. Agricultural and Forest Meteorology, 127(1): 35-51.

Perrier A. 1975a. Physical study of evapotranspiration in natural conditions. I. Evaporation and balance of energy of natural surfaces. Annales Agronomiques, 26: 1-18.

Perrier A. 1975b. Physical study of evapotranspiration in natural conditions. III. Actual and potential evapotranspiration of canopies. Annales Agronomiques, 26: 229-243.

Prenger J J, Fynn R P, Hansen R C. 2002. A comparison of four evapotranspiration models in a greenhouse environment. Transactions of the ASAE, 45(6): 1779-1788.

Qiu R J, Kang S Z, Du T S, et al. 2013. Effect of convection on the Penman-Monteith model estimates of transpiration of hot pepper grown in solar greenhouse. Scientia Horticulturae, 160: 163-171.

Qiu R J, Du T S, Kang S Z. et al. 2015. Influence of water and nitrogen stress on stem sap flow of tomato grown in a solar greenhouse. Journal of the American Society for Horticultural Science, 140(2): 111-119.

Rajan N, Maas S J, Kathilankal J C. 2010. Estimating Crop Water Use of Cotton in the Texas High Plains. Agronomy Journal, 102(6): 1641-1651.

Rouphael Y, Colla G. 2004. Modelling the transpiration of a greenhouse zucchini crop grown under a Mediterranean climate using the Penman-Monteith equation and its simplified version. Australian Journal of Agricultural Research, 55(9): 931-937.

Shuttleworth W J, Wallace J S. 1985. Evaporation from sparse crops-an energy combination theory. Quarterly Journal of the Royal Meteorological Society, 111(469): 839-855.

Stannard D I. 1993. Comparison of Penman-Monteith, Shuttle worth-Wallace, and modified Priestley-Taylor evapotranspiration models for wildland vegetation in semiarid rangeland. Water Resources Research, 29(5): 1379-1392.

Stanghellini C. 1987. Transpiration of greenhouse crops: an aid to climate management. PhD Dissertation. Wageningen: Wageningen Agricultural University, 31-88.

Stanghellini C. 1993. Mixed convection above greenhouse crop canopies. Agricultural and Forest Meteorology, 66(12): 111-117.

Thom A S, Oliver H R. 1977. On Penman's equation for estimating regional evaporation. Quarterly Journal of the Royal Meteorological Society, 103(436): 345-357.

Villarreal-Guerrero F, Kacira M, Fitz-Rodríguez E, et al. 2012. Comparison of three evapotranspiration models for a greenhouse cooling strategy with natural ventilation and variable high pressure fogging. Scientia Horticulturae, 134: $210-221$.

Wang S, Boulard T, Haxaire R. 1999. Air speed profiles in a naturally ventilated greenhouse with a tomato crop. Agricultural and Forest Meteorology, 96(4): 181-188

Wei R J, Sun Z F. 2014. Development and perspective of research on microclimate of sunlight greenhouse in china. Journal of northwest A\&F university (Natural Science Edition), 42(12): 139-150. (in Chinese)

Yang X S, Short T H, Fox R D, et al. 1990. Transpiration, leaf temperature and stomatal resistance of a greenhouse cucumber crop. Agricultural and Forest Meteorology, 51(3-4): 197-209.

Yuan B Z, Kang Y H, Nishiyama S. 2001. Drip irrigation scheduling for tomatoes in unheated greenhouses. Irrigation Science, 20(3): 149-154.

Zhang L, Lemeur R. 1992. Effect of aerodynamic resistance on energy balance and Penman-Monteith estimates of evapotranspiration in greenhouse conditions. Agricultural and Forest Meteorology, 58(3-4): 209-228.

Zhang B Z, Kang S Z, Li F S, et al. 2008. Comparison of three evapotranspiration models to Bowen ratio-energy balance method for a vineyard in an arid desert region of northwest China. Agricultural and Forest Meteorology, 148(10): $1629-1640$.

Zheng H, Yu G R, Wang Q F, et al. 2016. Spatial variation in annual actual evapotranspiration of terrestrial ecosystems in China: Results from eddy covariance measurements. Journal of Geographical Sciences 26(10): 1391-1411. 